Number 1

January 2006

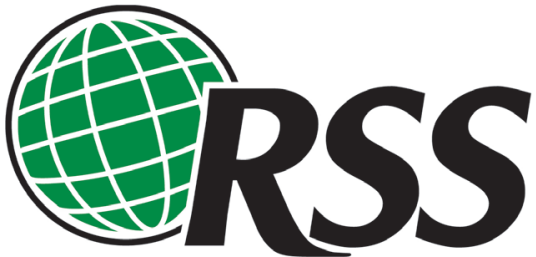

RURAL SOCIOLOGICAL SOCIETY

\title{
The Changing Face of
}

\section{Rural America}

\begin{abstract}
A fter a decade of population loss, rural America has seen its population grow again. Nearly threefourths of the 2,303 counties classified as rural in 1993 gained population between 1990 and 2000. As of April 2000, these areas collectively boasted a population of 56.1 million - about one in five Americans - and 5.2 million more than in 1990. Rural areas continued to gain population after 2000, but the pace of growth slowed considerably from that of the 1990s. (See Figure 1 for population changes across two decades.)
\end{abstract}

Population growth, however, is only one of many changes affecting rural areas. Rural America today has moved from predominantly agrarian to postagrarian - fewer than one in ten rural families earns its livelihood from the land - and various economic, technological, and social changes have fundamentally altered rural life. This brief, based on Kenneth Johnson's chapter in Challenges for Rural America in the TwentyFirst Century, explores these changes and their effects on rural America. ${ }^{1}$

\section{Population Changes}

The population gain since 1990 has been driven primarily by migration, accounting for approximately two-thirds of the growth, a phenomenon that has also increased diversity within rural areas. Minorities constituted

Figure 1. Percentage Change in Population, 1980 to 1990, by residence

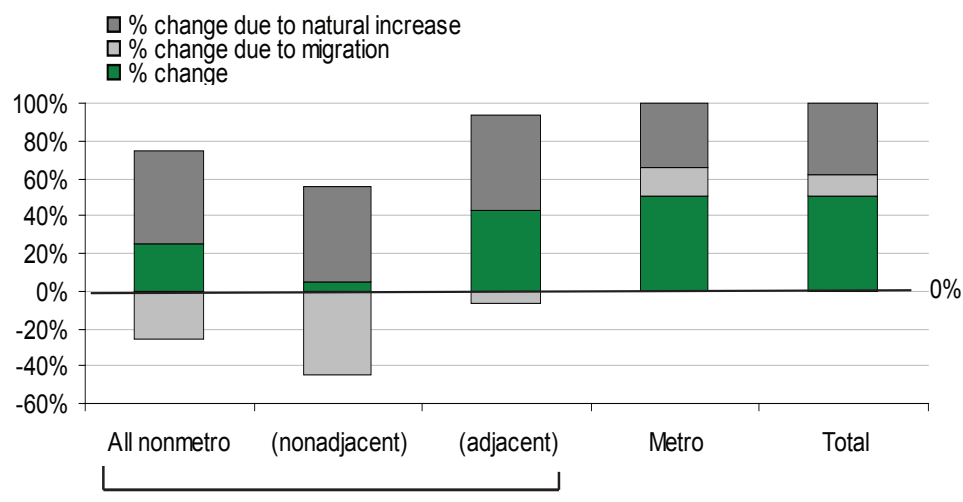

Percentage Change in Population, 1990 to 2000 , by residence

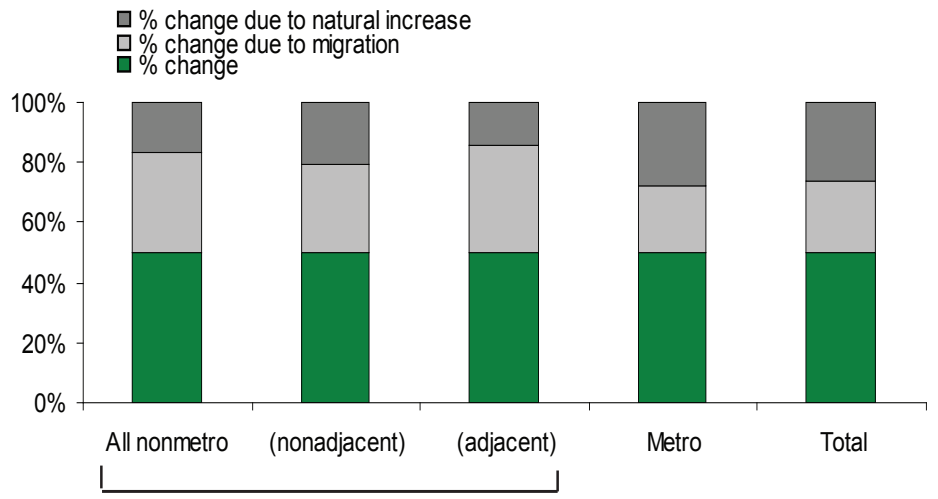
nearly $39 \%$ of the population gains in nonmetropolitan counties. Latinos are one of the larger minority groups moving to rural counties, bringing both the benefits of their labor and challenges to communities seeking to provide education and social services to them.

1 David L. Brown and Louis E. Swanson, editors, Challenges for Rural America in the Twenty-First Century (University Park, PA: Pennsylvania State University Press, 2003). This brief draws mainly on chapter 1, "Unpredictable Directions of Rural Population Growth and Migration," by Kenneth Johnson (Loyola University, Chicago). 
Rural population growth since 1990 has not been evenly distributed throughout the United States. Counties dependent on agriculture, mining, or those with histories of persistent poverty were the least likely to grow, while rural counties adjacent to metropolitan areas were more likely than nonadjacent counties to gain population. Counties with a large proportion of their workforce in the service sector or commuting to jobs in other counties grew rapidly, owing mainly to net migration gains. Nonmetro counties with significant amenities or quality of life advantages also saw particularly sharp growth, continuing trends begun in the 1970s. (See Brief no. 3 for more on amenity-based economic growth.)

\section{Restructured Families, Restructured Communities}

Today's rural families bear little resemblance to those of 50 years ago. Large, intergenerational families are largely a thing of the past. Not only are rural families now smaller - roughly comparable to urban families in size - but rural communities have seen an increase in divorce and single-parent families (see Figure 2). Elderly rural residents are less likely than urban elderly to live with family members, and rural residents 65 years and older compose $26 \%$ of the population compared with $22 \%$ of the urban population. The rural elderly also no longer have an advantage over urban residents Figure 2. Proportion of Female-Headed Households, by location in the availability of a spouse as a potential caregiver, even though they have a greater need for such support than urban older people, given their higher rates of disability and morbidity.

Many rural residents no longer work at local jobs. As the number of agricultural jobs declined, local businesses that relied on a farm-

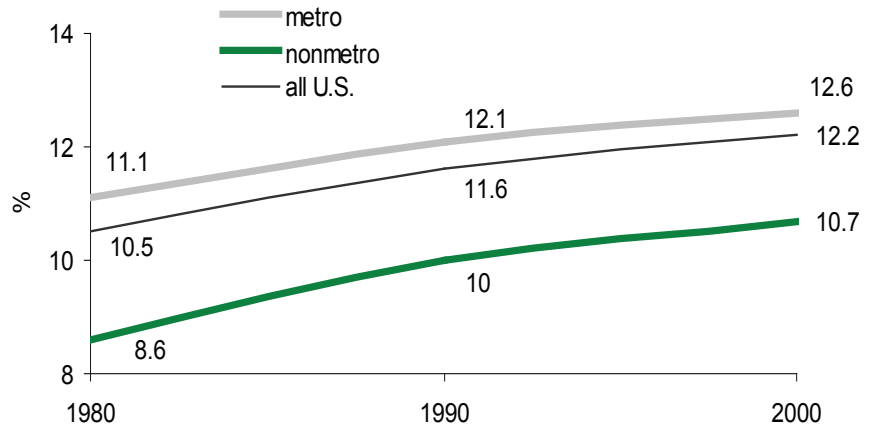
based economy also struggled. In addition, globalization has cost jobs in rural areas - particularly in the South - as low-skill manufacturing production moves offshore. As a result, many rural adults now must commute longer distances to work. Further, as men have lost well-paying jobs in mining, forestry, and manufacturing, women in some rural areas have become their family's sole breadwinner, in addition to the family caregiver. However, the jobs, typically in the service sector, are often low-paid with few benefits, risking rising poverty among families. Work and family obligations are compounded by the fact that rural families must provide for a higher ratio of dependents (both children and the elderly) than urban families, despite much less access to formal support services such as center-based child and elder care. All of these changes have had a profound effect on rural families and communities.

\section{Minority Populations Revisited}

The increasing diversity of rural America deserves a closer look at the racial-ethnic populations making up the rural landscape. As a whole, racial-ethnic minorities, whether because of historical racism or language, cultural, or other barriers, often fare worse on several indicators than whites.

Currently, approximately one-half of the 500 counties classified as "persistent poverty counties" stretch 
across the heart of the old plantation South. A persistent poverty county has had poverty rates $20 \%$ or higher in each of the decennial censuses since 1960. The majority of these counties make up the Black Belt, the largest expanse of rural poverty within the United States. (See Brief no. 2 for more on poverty.) The Black Belt contains $79 \%$ of the rural African American population and $45 \%$ of all African Americans. Rural African Americans lag significantly behind whites and urban African Americans in educational achievement. In 2000, only $8.1 \%$ of rural African Americans aged 25 and Figure 3. Percentage Change in Latino Population, 1990 to 2000 over had earned bachelors' degrees or higher, compared with $21.4 \%$ of rural whites, $34 \%$ of urban whites, and $19.5 \%$ of urban African Americans.

Latinos have a wellestablished presence in U.S. border communities, and they have recently begun to migrate to rural areas $\square$ nonmetro $\square$ metro outside the Southwest, in particular for construction and meat packing jobs in the Midwest and Southeast. The Latino population, the fastest growing racial or ethnic population in the United States, increased by about 58\% between 1990 and 2000. Latino population growth was actually higher in rural areas during the 1990 s, increasing by $67 \%$ compared with $57 \%$ growth in urban areas (see Figure 3 for regional population trends).

Rural communities will continue to recruit, attract, and depend heavily on the Latino workforce. Yet while Latinos have much to offer their communities, they also have numerous needs, and meeting those needs helps them to contribute to the development and sustainability of rural communities. These needs include access to health care, which this population tends to underuse, and educational programs that are sensitive to Latino culture and language. The 2000 Census data show that $45.1 \%$ of rural Latinos aged 25 and older had not finished high school compared with $25.4 \%$ of rural African Americans and $10 \%$ of rural whites.

Roughly one-half of all American Indians reside in rural areas. By nearly any measure, they have less income, lower educational attainment, higher unemployment, and higher poverty rates than non-Indians. Disparities in mortality and morbidity are also acute: American Indians suffer from 2.5 times the average rate of diabetes in the country, 33 times the average rate of fetal alcohol syndrome, and 533\% higher rates of tuberculosis. These conditions apply to American Indians residing in urban as well as rural areas. In addition, because of the geographic isolation of rural Indian reservations, most lack adequate access to roads, utilities, housing, and telecommunications. Although tribal gaming has benefited some Indian tribes by providing jobs and funding for tribal governments and services, the long-term effects of this form of income on cultural values, practices, and traditions is still unknown. More important, fewer than one-half of the 562 Indian tribes formally recognized by the federal government operate casinos. 


\section{Policy Implications}

This issue brief is a joint product of the Rural Sociological Society and the National Coalition for Rural Entrepreneurship, a collaboration of four Regional Rural Development Centers: The Northeast Regional Center for Rural Development, the Southern Rural Development Center, the North Central Regional Center for Rural Development, and the Western Rural Development Center. Funding was also made available from the Ford Foundation. For more information, see http://ruralsociology. org. Or contact RSS at 104 Gentry Hall, Univ. of Missouri, Columbia, MO 65211. Phone: 573-/882 9065. Throughout the series, the terms "rural" and "nonmetropolitan" are used interchangeably.
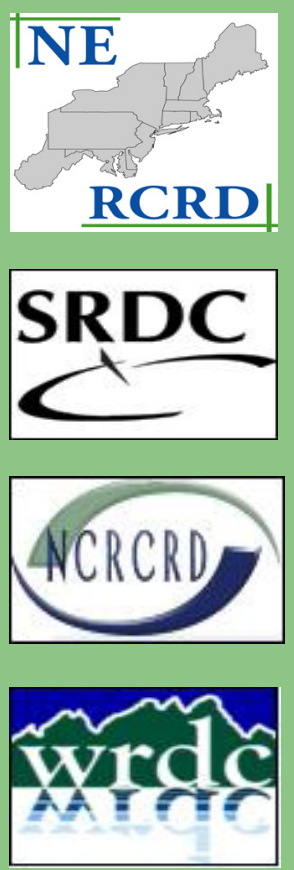

The postagrarian economy that marks most rural areas in the United States (see Figure 4), as well as the process of devolution and deregulation in governing (see Brief no. 4), present significant challenges for rural populations and communities. Many rural areas have scant, if any, formal social services available to their residents. Those that currently exist are likely to be severely stressed by commuting parents who need child care and afterschool programs, elderly residents who do not live near a child or do not have a spouse who can assist them, Latino immigrants who need assistance in English, and many other needs

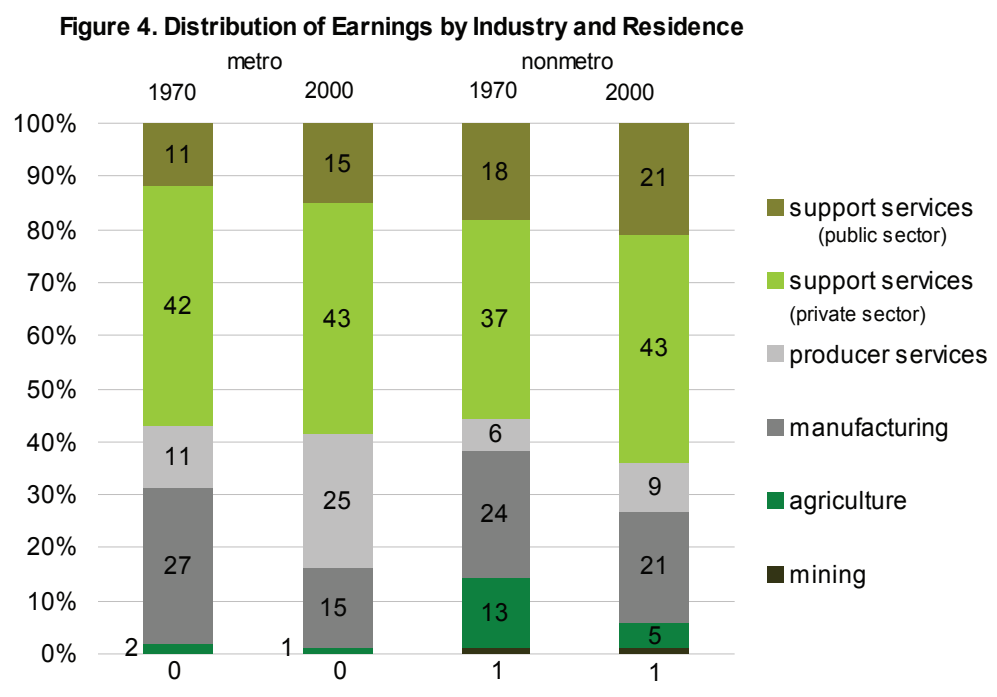
that people have as they rear children, work, and grow old.
Unlike more heavily populated areas with accompanying economies of scale, local rural governments simply cannot afford to provide many social services and supports. Rural communities, however, could overcome some of these barriers if public policy supported their banding together in local regional groups with other communities to share resources and staffs, and to combine the efforts of community-based and nongovernmental organizations. In addition, flextime and family-friendly policies would help rural families balance long commutes with family obligations.

Because residents of rural areas lag behind their urban peers in educational achievement, improving education levels, especially among minority youth, is imperative given both their growing importance to the community and their lower education levels. (See Brief no. 5 on rural educational strategies.)

The loss of low-skill jobs to globalization suggests that additional efforts to increase educational achievement are important so that rural communities are more attractive to businesses. Alternatively, entrepreneurship educational programs in financial literacy and technical assistance on access to capital, marketing, and business regulations increase the potential for local enterprise and employment growth.

Finally, the loss of farmland, extensive commuting by rural residents, and low-density housing suggest that issues of land use, delivery of services, and physical and broadband infrastructure improvement should also be included in policy discussions about the future of rural areas and residents. 